Meta

Journal des traducteurs

Translators' Journal

\title{
Ut Once More: The Sentence as the Key Functional Unit of Translation
}

\section{Chunshen Zhu}

Volume 44, numéro 3, septembre 1999

URI : https://id.erudit.org/iderudit/004644ar

DOI : https://doi.org/10.7202/004644ar

Aller au sommaire du numéro

\section{Éditeur(s)}

Les Presses de l'Université de Montréal

ISSN

0026-0452 (imprimé)

1492-1421 (numérique)

Découvrir la revue

Citer cet article

Zhu, C. (1999). Ut Once More: The Sentence as the Key Functional Unit of Translation. Meta, 44(3), 429-447. https://doi.org/10.7202/004644ar
Résumé de l'article

La linguistique de texte permet aux traducteurs de "progresser", de travailler le texte de façon plus efficace et donne une "autorité textuelle judiciaire". Elle doit leur permettre également de "regarder de haut??" les unités inférieures en tant qu'unités fonctionnelles grâce à la textualité. En principe, les discussions sur la traduction portent plus souvent sur des passages localisés plutôt que sur les textes complets et la notion d'unité de traduction (UT), une fois bien définie, est alors jugée utile pour combler le fossé technique qui existe entre le texte entier et ses composantes en décrivant les relations engagées dans la traduction, en termes de responsabilité potentielle d'un passage localisé envers le texte. Cet article aborde la question de l'UT du point de vue de la division du travail en traduction entre mémoires à court et à long terme et la définit fonctionnellement en tant qu'unité textuelle, plutôt qu'unité de langage, conservant son intégrité textuelle par l'accomplissement de trois fonctions i.e. porteur syntaxique, transporteur d'information et marqueur stylistique. La traduction de textes se ramène donc au maintient d'une telle intégrité textuelle de chaque unité de traduction non pas sous sa forme syntaxique mais par sa fonction, suivant les changements de rangs nécessaires durant de processus. À cette fin, l'UT clé fonctionnelle peut être déterminée au niveau de la phrase.Cet article est une version revue de la première partie de Zhu (1996a).
Ce document est protégé par la loi sur le droit d'auteur. L'utilisation des services d'Érudit (y compris la reproduction) est assujettie à sa politique d'utilisation que vous pouvez consulter en ligne.

https://apropos.erudit.org/fr/usagers/politique-dutilisation/ 


\title{
Ut Once More: The Sentence as the Key Functional Unit of Translation
}

\author{
chunshen $\mathrm{zhu}$ \\ City University of Hong Kong, \\ Hong Kong, China
}

\begin{abstract}
RÉSUMÉ
La linguistique de texte permet aux traducteurs de «progresser», de travailler le texte de façon plus efficace et donne une «autorité textuelle judiciaire». Elle doit leur permettre également de «regarder de haut? ? 》 les unités inférieures en tant qu'unités fonctionnelles grâce à la textualité. En principe, les discussions sur la traduction portent plus souvent sur des passages localisés plutôt que sur les textes complets et la notion d'unité de traduction (UT), une fois bien définie, est alors jugée utile pour combler le fossé technique qui existe entre le texte entier et ses composantes en décrivant les relations engagées dans la traduction, en termes de responsabilité potentielle d'un passage localisé envers le texte. Cet article aborde la question de l'UT du point de vue de la division du travail en traduction entre mémoires à court et à long terme et la définit fonctionnellement en tant qu'unité textuelle, plutôt qu'unité de langage, conservant son intégrité textuelle par l'accomplissement de trois fonctions i.e. porteur syntaxique, transporteur d'information et marqueur stylistique. La traduction de textes se ramène donc au maintient d'une telle intégrité textuelle de chaque unité de traduction non pas sous sa forme syntaxique mais par sa fonction, suivant les changements de rangs nécessaires durant de processus. À cette fin, l'UT clé fonctionnelle peut être déterminée au niveau de la phrase. Cet article est une version revue de la première partie de Zhu (1996a).
\end{abstract}

\section{ABSTRACT}

Text linguistics enables translators to "climb up," to work more effectively from the level of text with "textual judicial authority." It should enable them to "look down" as well at lower units as functional units. Technically, discussions of translation often treat localized passages rather than full texts. The notion of Unit of Translation (UT), once defined, is thus useful for bridging the technical gap between the full text and its components in describing relationships involved in a translation, and looking at a localized passage's potential accountability to the whole text. This article approaches the issue of UT from the point of view of division of labour between short-term and long-term memory in translating, and defines the UT functionally as textual unit instead of language unit which maintains its textual integrity by performing three functions, viz. syntatic bearer, information carrier, and stylistic marker. Text translation thus boils down to the preservation of the textual integrity of each UT not in syntactic form but in function, given the necessary rank-shifts in the process. To that end, it argues, the key functional UT can be set at the level of sentence. The article is a revised version of the first part of Zhu (1996a).

\section{INTRODUCTION}

In actual translation practice, analysis and teaching, examination is needed to clarify the relationship between the text and its constituent parts as Units of Translation (UT). Examination makes the latter textually significant and thus accountable within translation, a process that reconstructs the structure of the source text in the target language and culture. 
Put in a down-to-earth manner, good translating, like good writing, comes from the right choice of words and word order. The only difference is that in translating, this "right choice" is prompted and at the same time restricted by the existing SL text as well as by the resources available in the target language. This "rightness," or appropriateness, has engaged the attention of translation theorists and practitioners for centuries. In dealing with this dilemma, however, they encountered another problem of "rightness": diceding what length of discourse can most propitiously serve as a unit of practice and analysis. This has been a core issue underlying the concept of UT, a concept that is both "a concrete reflection of the age-old conflict between free and literal translation" (Newmark 1988: 54), and "a basis for a scientific approach to translation" (Snell-Hornby 1990: 81). This is also where disagreement starts, rendering the notion of UT of hardly any assistance to translators in practice (Newmark 1981: 140 and 1988: 54) until key issues such as criteria, linguistic basis, and form and content, can be clarified (Barkhudarov 1993).

\section{DISAGREEMENT ABOUT THE RANGE AND SCOPE OF THE UT}

Catford, following Halliday, proposes a systemic hierarchy of five units for consideration in translating. They are, in descending order, the sentence, clause, group, word and morpheme (Catford 1965: 8). Newmark, while maintaining that "free translation has always favoured the sentence; literal translation the word," has observed that with text linguistics, free translation has moved to the whole text, i.e., to regarding the whole text as the UT, and has given rise to a "confusing tendency" (Newmark 1988: 54). His schema of hierarchical ranking, in consequence, ranges from the complete text, to the paragraph, sentence, clause, word group, word, morpheme and punctuation marks (Newmark 1988: 9), while a later version (Newmark 1988: 65-66) excludes punctuation marks but includes the collocation, which is, in turn, left out in a still later system of "main descriptive units" (Newmark 1991: 66).

Ballmer (1981), on the other hand, has noted in sentence and text linguistics "a hierarchy of levels beginning with phonemes and morphemes and progressing to words, phrases, sentences, and texts," on which "linguistic entities" such as utterances and discourses can be accounted for. In Hatim and Mason (1990: 132), however, the hierarchy, as a "convenient methodological device for handling intertextuality," has progressed from the word, phrase, clause and clause sequence, to the levels of text, discourse and genre.

Can all these language units or levels be regarded as operative UTs? Should any of them be adopted as the basic unit(s) to facilitate the actual translating practice? Such issues have yet to be clarified theoretically.

On the one hand, it is apparent that use of the morpheme as a unit is fading; on the other hand, the importance of units larger than the sentence or clause sequence is on the increase (cf. Holmes 1988: 75 and Snell-Hornby 1990; Larson 1984: chs.29, 36 and 37). Halliday (1978: 70) himself, when taking the text as a semantic unit, points out:

The essential problem [...] is that [...] of relating the text not only "downwards" to the sentences which realize it but also "upwards" to a higher level of meaning, of which it is itself the realization or projection. 
The inclusion of the text reflects an increase in the scope of linguistic and translation studies to cover communicative factors such as intention, attitude and social appropriateness in language use in the form of textualization, rather than concentrating merely on "minute" linguistic details at lower levels. This has been hailed by SnellHornby (1988: 20-21) as "a remarkable step forward" when referring to Filipec's text-based notion of "structural equivalence."

Further along the line of text linguistics, then, there emerges a notable distinction between the concept of "complete text" (qua artifact) and that of "text" (qua process). The latter, referred to in more specific theories as discourse (cf. Bell 1991: 149 and ch. 5), consists of any coherent and cohesive unit that realizes a specific speech act or speech-act sequence. This notion of text serves to reveal the impracticality of taking the "full text" as the UT. At the same time it recognizes, albeit indirectly, the functional status of the sentence in the process of textualization in translating. This further reveals the dependence of text linguistics on sentence linguistics for the analysis of a text's physical as well as stylistic features. Bell, for instance, has observed a similarity in nature between the text and the sentence, as both are "a structured sequence of linguistic expressions forming a unitary whole" (Bell 1991: 162, quoting Edmondson); Snell-Hornby (1988: 121) has also postulated a "top-down procedure" in stylistic analysis which leads down to the micro-levels below the macro-level of text-structure.

Individual translators, with different foci of attention, may prefer different units as their basic working UTs. For instance, Bassnett-McGuire's (1980: 117) "prime unit" is the (full) text, Tancock's (1958: 33) "most satisfactory unit [...] is the rather long sentence or short paragraph," while Bell (1991: 29) suggests that "the unit tends to be the clause" and Zhang (1994: 155, 230) holds the sentence as the "core unit in translation." Others prefer to adopt a more flexible notion of the UT. Newmark (1988: 67), for instance, has declared that his perception of the UT is as "a sliding scale;" Hatim and Mason (1990: 78), by introducing the "text act" as the level on which "equivalence may also be judged," have in fact transcended the physical boundaries of the UT in the traditional sense. Sager (1994) maintains that "the text type is the largest [textual] unit [...] the prime class of units" (p. 89) and UTs "are flexible and a matter of cognitive and linguistic factors" (p. 222), whose size "can be established at the level of the text or the message, or at the lower levels of the sentence, phrase or word" (p. 225).

Those who have taken exception to the (full) text as the UT, including Newmark, argue that "That would be chaos," and "Ideally, the UT is one word [...] never the text" (Newmark 1981: 140, 1988: 55). Those who hold the (full) text as the UT either warn that the translator "must never dwell on the words of his author" (O'Brien 1959/66: 84 , quoting Dryden), or insist that the translator "must eventually resolve to translate discourse equivalents, rather than lexical or even sentential structures" (Givón 1978: 272).

It is worth noting that what underlies these contending arguments is a common (mis)belief that the sentence and the (full) text are mutually exclusive units; or, that textual/discoursal meaning is independent of the structures of the constituent sentences. It is in the interest of translation studies at least to clarify the status and function of the sentence in text organization; that is, to find out in what respect sentential structures are responsible for and contributory to the construction of 
textual structures, and how the textual intention (e.g. in terms of macro-speech-act) determines the formation of a sentence. This is one of the issues dealt with in this article.

\section{THE UT REDEFINED}

The disagreement illustrated above calls first of all for a definition of the UT and an assessment of its usefulness in translation studies. Newmark's definition of the UT, based on Vinay's and Darbelnet's concept and Haas's description (both referred to in Newmark 1988: 54), offers a succinct summary of the traditional view:

The smallest segment of an SL text which can be translated, as a whole, in isolation from other segments. It normally ranges from the word through the collocation to the clause. It could be described as "as small as is possible and as large as is necessary" (this is my [i.e. Newmark's] view), though some translators would say that it is a misleading concept, since the only UT is the whole text. (Newmark 1988: 285)

Current thinking on definition is essentially formal rather than functional. One can talk about translating a language unit in terms of physical, i.e. formal, "isolation" with regard to meaning and function. Every unit should be a part of the structure on a higher level (see Toury 1995: 85-86). Such a formalistic view, which sees the text "as a linear sequence of units" and translation as "merely a transcoding process" "determining the translation units and selecting the so-called 'optimal equivalent"' (SnellHornby 1988: 16, original italics), is discernible in the literature's concern with issues such as the "size" or "length" (instead of the function) of the UT.

The definition, which suggests an equation of the UT with notions such as language unit and language level, reveals Newmark's apparent vacillation about the range of the UT. Elsewhere he has stressed the importance of the sentence, conspicuously absent in the above definition, as the "natural" or primary UT, while those below the sentence are "sub-units of translation" (Newmark 1988: 31, 65). He has even specified the sentence as "the basic unit of translating (not of translation)" (Newmark 1991: 66, original italics), although he does not seem to insist on the unexchangeability of the two terms on other occasions (see Newmark 1988: 30-31).

In fact, there is ambivalence in Newmark's general attitude towards the notion of UT. For instance, he had once dismissed notions such as the UT and translation equivalence as "dead ducks" that were "either too theoretical or too arbitrary" (Newmark 1981: x; also noted in Snell-Hornby 1988: 21). However, he later reopened the case, ranking the UT with discourse analysis to form a full-length chapter (Newmark 1988: ch. 6). Elsewhere he regarded translation equivalence, as well as the UT, as "sometimes a useful operational concept" (Newmark 1991: 33) in dealing with more "challenging" texts on a, say, paragraph-for-paragraph basis. Newmark has certainly sensed the usefulness of the UT in classifying and clarifying some conceptual and technical issues in translation theory, but within the confines of a formalistic view he has found (probably subconsciously) that a coherent perception of the matter is somehow unattainable. This helps to explain why the (size of the) UT, as an issue, has "exercised translators and translation theorists for centuries" (Bell 1991: 161).

The formalistic view of the UT is responsible, at least partly, for the aforementioned lack of agreement among theorists with regard to the level(s) of the UT. It 
must be pointed out that contending views as to whether the sentence or the entire text should be held as the UT are actually traceable to what Ballmer (1981: 164-165) describes as "the strict sentence linguistic position" and "the strict text linguistic position." In our study, however, we adopt the third attitude, "the sentence and text differentiating position," which holds that

sentences and texts constitute two levels with a sufficient number of differences to make it a worthwhile enterprise to first study the two levels independently and then to work out their relations in detail. (Ballmer 1981: 165)

The very nature of textuality determines that nothing in a text can be treated in isolation, so it is important to maintain the UT as an independent but not isolated unit. The discussion so far has led us to propose a working redefinition of the UT to facilitate the rest of the study:

The smallest segment of an SL text which can be translated as an independent and integrated meaning entity in relation to other segments of the text. Its formal realization, if viewed in isolation, is analyzable on levels ranging from the morpheme to the sentence; its textual potential, however, is based on the completeness of its information structure, and is normally realized when it performs textual functions in the SL text. These textual functions are to be matched in the construction of a TL text.

The linguistic basis of the textual functions of the UT as defined above constitute a potential meeting point between the SL text and the TL text where "translating" takes place, and from where phenomena such as "rank-shifts" can be better observed in the light of textuality.

\section{THE UT AND TRANSLATION EQUIVALENCE}

In translation studies, the issue of UT is frequently raised in conjunction with that of translation equivalence. As Sager (1994: 222) puts it, both "lie at the heart of any theoretical or practical discussion about translation." This is because theorists, consciously or subconsciously, take the UT as a compartment in which what they believe to be "translation equivalence" materializes. As two theoretical concepts, however, they should be regarded distinct from each other. The notion of translation equivalence, which "implies that complete equivalence is an achievable goal" (Hatim and Mason 1990: 8), is indicative of a belief in the existence of an "absolute" meaning or identity (cf. Eoyang 1993: 14, 15). Such an absolute-meaning-based notion of equivalence is open to challenge from various points of view, including etymology (Snell-Hornby 1988: 16-22), transformational grammar (Q. Hu 1993, 1994) and Deconstruction (Koskinen 1994).

It is acceptable that the SL text does possess an absolute ontological form, but in the reality of reading and understanding, an absolute textual form can produce no such thing as absolute (i.e. transcendental, ahistorical, or eternal) meaning. The entropic nature of human communications, which involves variations in the form of (inevitable) loss and (unexpected) gain, is significant for our understanding of the (lack of) equivalence in information reception and hence translation (cf. Neubert and Shreve 1992: 2, Tan et al. 1992: secs. 4.1 and 4.4). A text's meaning is subject to the personal particulars of the reader and the process of his/her reading. In other words, the putative meaning is the outcome of an interaction between the text, the 
reader and the reading. Translating is based on usually more than one (close) reading performed by the translator, which eventually gives birth to the TL text, another absolute ontological form whose meaning is similarly relative and subject to what Mason (1994: 25) calls the "discursive history" (i.e., the language user's "previous experience of discourse") and the actual reading process of individual TL readers.

Technically at least, then, there are only two verifiable types of source-target text comparison. One is between two absolute forms, or the texts' "absolute and sacrosanct locutionary autonomi[es]" in Petrey's (1990: 70) terms, thus a static formal comparison in the first, linguistic dimension of SOM (Structure of Meaning, cf. Zhu 1996b). It is useful for language learning and perhaps for developing critical sensitivity to the texture of a text, but not so much for translating. The other type of comparison is between the illocutionary meanings derived (ideally) in the same process of reading of the texts by the same reader; thus for the translator or critic, the "one person par excellence [...], at least briefly, ST [source text] and TT [target text] are not separated but on the contrary are simultaneously present and intimately interconnected in his or her mind" (Harris cited in Toury 1995: 96). This second type is a text-based but reader-centred dynamic functional comparison which draws on the first dimension of SOM as its material basis, consequently involves the second, interactional dimension of SOM, and has substantial implications for the third, aesthetic dimension. This comparison is essential to the study of translation. It is little surprise that, failing to take into consideration the relativity of the meaning derived from each reading, an absolute-meaning-oriented endeavour to seek complete or pure equivalence in translation has produced more contradictory speculation (see, e.g. those must's and should's referred to in Wilss 1982: 134) and terminological elaboration (as referred to in Snell-Hornby 1988: 19-21) than truth and insight. ${ }^{1}$

Viewing the UT as a language level on which translation equivalence is to be established is, therefore, a misguided conception based on three unwarranted beliefs: (a) a UT is a formal unit in nature and can be treated in isolation; (b) language units are automatic UTs; and (c) complete equivalence is achievable. To restore the concept of UT to its true functional status, it is of vital importance to keep the UT and translation equivalence as two separate notions. Then, the UT will not be invalidated on the grounds of the implausibility of translation equivalence, so long as the application of the UT does not base itself on the purported "absolute meaning" or formal identity in theory and seeks nothing of the kind in practice.

\section{LANGUAGE UNIT: ITS TRIPLE NATURE IN TL TEXT CONSTRUCTION}

Before we proceed to identify a functionally more accountable UT, it is necessary to examine what one may have expected a language unit (not yet a UT) to be in the construction of the TL text. Do we expect a unit suitable for translating

(a) to be processible in short-term memory,

(b) to be syntactically comparable to its SL counterpart,

or

(c) to have the ultimate textual judicial authority? 
Once we view a language unit in this light, we realize that understanding a language unit as a UT may involve the risk of packing into the notion of UT expectations that are not fully compatible, and which render it useless in practice.

A unit processible in short-term memory, ceteris paribus, must contain an amount of information that is limited enough to maximize the "ease of recall" and minimize the "degree of effort" in text comprehension (cf. Cowan 1995: 30), or enables controlled cognitive processing (cf. Kiraly 1995: 85, see also pp. 67-68 for "controlled processing" as against "automatic processing"). Such a unit can and should be approached not only in "the narrative mode" but, more importantly, in "the paradigmatic or logico-scientific mode" of understanding. ${ }^{2}$

By localizing a unit in short-term memory, translators can be more efficient in retrieving and reproducing their perception of the information the unit carries. They can also maximize their reading experience along the presentation of the information before the complexity of the experience is transformed into "simple understanding," with its linguistic/textual irregularities (i.e. potential stylistic markers, see Section 6 below) thus repressed (cf. Schleifer et al. 1992: 38-39, 41). In other words, for a language unit to be an operative UT, it has to be processible in short-term memory as a conceptual, linguistic and aesthetic experience that is paradigmatic or logico-scientific. It is then "contextualized" (simplified and reduced) to become the generalizable "knowledge" resident in long-term memory, that is required by the progression of the cognition of the SL text as a whole.

Cross-lingual short-term-memory processibility entails syntactic comparison between the two correspondent language units involved. (See Toury 1995: 88-89 for "the need for a unit of comparative analysis.") The TL unit is linguistically accountable for its textual validity against its SL counterpart, but is not extensive enough to make its judicial authority over its sub-units anything more local and preliminary. We argue that, in realistic and practicable terms, this unit is the sentence.

If sentences provide "linear coherence" for a local sequential comparison of information presentation, then the significance of the full text, as "the ultimate court of appeal" (Newmark 1991: 66), lies in its "global coherence" (after van Dijk 1977: 95), which supplies the authority to assess and quality-control the final product of translation. It should be pointed out that the full text itself has to be seen against its nonlinguistic or intertextual context; and that the perception of such a context depends heavily on the translator's reading capacities.

The introduction of the text as the ultimate judicial unit enables the translator to surpass the confines of the sentence as a grammatical unit. Only within the global coherence of the text can we be more aware of inter-sentential connections in the SL text and accordingly arrange to procure the global coherence of the TL text in translating. Such an ultimate judicial unit is normally too big to be processed in one go by short-term memory, even though the unit is structurally comparable between languages.

If we insist that the UT, as an "independent and integrated meaning entity" (our definition above), must acquire the ultimate textual judicial authority, then it should be placed at the level of the full text, or even at macro-textual and contextual levels. Thus, we find ourselves in a dilemma, as it is virtually impossible to retain the intricate structure of a complete text in short-term memory - that is, to translate a whole text "in one fell swoop," as Harris puts it (cited in Toury 1995: 96). Any 
exercises of this kind go against the law of efficiency and energy conservation in cognition because of our limited capacities to process information. Informational accuracy and stylistic effectiveness would suffer as a result.

\section{TEXTUAL INTEGRITY OF A TEXTUAL UNIT: ITS THREE FUNCTIONS}

If we agree that short-term-memory processibility and syntactic comparison are requirements if a language unit is to become a UT - requirements of a more fundamental importance than judicial authority - then we have to find out what aspects a UT yields to logico-scientific analysis. This is where the concept of textuality (determined by seven features: cohesion, coherence, intentionality, acceptability, informativity, relevance and intertextuality) becomes important for translation (see Neubert and Shreve 1992: viii, 15 and 69; and Bell 1991: sec. 5.1). A language unit has to therefore be viewed in terms of its textual potential before it can function as a UT. ${ }^{3}$

In the process of text formation the semantic and syntactic resources of a language are brought into full play within the physical contour of a textual unit in order to realize the formal cohesion and conceptual coherence of the text. Cohesion and coherence, in turn, constitute the material and cognitive basis for the other components of textuality. All of these aspects of textuality require a textual unit to be grammatically appropriate and acceptable. They also require it to contain information that makes sense contextually and that renders the text in conformity with its genre membership but with sufficient individuality to be distinct from other texts of the same type. A textual unit should be able to perform at least three functions:

(1) that of syntactic bearer: it has to be grammatically appropriate in order to provide a material basis for textual cohesion and coherence;

(2) that of information carrier: it has to convey ideationally and interpersonally significant messages (coherence) that render the text informative and relevant (informativity and relevance);

(3) that of stylistic marker: it has to contribute to textual organization by means of a judicious paradigmatic choice of words and syntagmatic choice of word-order; in this way its mode of information presentation can serve the textual intention better (intentionality), and the text's genre membership and textual individuality (intertextuality) can be more effectively accepted (acceptability).

A look at the pronoun or pronominal phrase as a textual unit illustrates these points. A pronoun as a syntactic bearer can fill the slot of subject, attribute or object, but not the slot of predicate or adverb. As an information carrier, a pronoun can function as the agent or patient in a transitivity structure and the topic or focus in an information structure. When it stands for a certain referent in the universe of discourse, a certain discourse value is attributed to it, such as anaphora or cataphora, that has a direct bearing on the macro-distribution of information in terms of knowledge sharing and transmission and, as a result, steers the progress of discourse (see McCarthy and Carter 1994: 90-93). Besides acting as a syntactic bearer and information carrier, a pronoun, when viewed as a stylistic marker, can play many roles in shaping the text. For instance, it not only helps determine the interpersonal distance (e.g. a specific I as against an involving we), but also enables the categoriza- 
tion of a piece of narration by the point of view which governs the angle and depth of narration and description.

Syntax bearing, information carrying, and style marking serve, on the one hand, to reveal the textual potential of a grammar-based language unit in terms of its applicability to a text. On the other hand, the functions postulate a set of three criteria for the linguistic accountability of a textual unit's performance, which, while retaining the essence of textuality, seems more operable for a practitioner. If such accountability has been crucial in the creation of the source text, it has to be equally so in the creation of the target text. In textualization, these functions combine to govern the ordering of what Ballmer (1981: 174) calls "partial incomplete linguistic entities (e.g. words)" to form "complete entities (e.g. sentences)" before adding the latter to "the (linguistic) context (e.g. texts)." In translating, a UT, being processible in short-term memory and comparable syntactically, acquires what can be called textual integrity by functioning as syntactic bearer, information carrier and stylistic marker. Its functions therefore have to be matched in the TL textualization. Realization of the status of the UT's textual integrity helps to mark the scope of the logico-scientific examination that will reveal the textuality induced by the linguistic surface (cf. Neubert and Shreve 1992: 70) in the SL text in esse, and therefore facilitate the actualization of a TL text in posse.

\section{THE PLAUSIBILITY OF TAKING THE TEXT AS THE "TARGET" INSTEAD OF AS A UNIT OF TRANSLATION}

Viewing a UT as a unit with textual integrity underlines the importance of the text as a language unit with ultimate judicial authority, and points to the necessity of placing the text in a more realistic status in relation to the concept of UT in the study of the practice of translation.

As Snell-Hornby has observed, the argument for unit-for-unit equivalence "rests on a shaky basis," which she identifies as the presupposition of "a degree of symmetry between languages which makes the postulated equivalence possible" (Snell-Hornby 1988: 16). Such a presupposition underlies a broader presumption that translation is conducted between two languages; however, it is more accurate to say that translation is carried out between two texts. This text-creation view of translation clearly influences comments such as "the translated text is a new creation which derives from close and careful reading [of the SL text], a reconstruction rather than a copy" (Bell 1991: 161, original italics), and is elaborated in my discussion of structure of meaning (Zhu 1996b). Since this new text is usually written in another language, the TL, the technical aspect of the translation act must consist of the employment of the TL's linguistic resources to ensure a desirable textual/functional correspondence as perceived by the translator.

The significance of this consensus about translation lies first of all in the substitution of the pursuit of textual/functional correspondence, largely attainable in terms of textual integrity, for the seeking of cross-language symmetry or identity, "an illusion [...] which hardly exists beyond the level of vague approximations and which distorts the basic problems of translation" (Snell-Hornby 1988: 22). This frees translators to perform correspondent textual functions in the formulation of the TL text. 
It also allows us to have a more realistic understanding of the text as a unit of language (or culture) than the unit of translation.

As a flexible, amorphous notion of the text (whether as one single sentence, a sequence of sentences, or an autonomous entity) reflects a basic problem in identification from a syntactic point of view (and does not help with the practicable application of the UT), we propose a combined definition of the text based on Ballmer (1981: 167, 179):

The text is an autonomous entity formed by a series of sentences with punctuation signs, to perform a single (macro-) speech act or a series of structurally-related speech acts.

This definition accords with Hewson and Martin's (1991: 91) description of a text as "a macro-proposition based on constituent units (propositions or sentences)." At the same time, it stresses the autonomy of the text and highlights a "downwards" link with the constituent sentences, and an "upwards" link with its communicative context via the speech act. All are important in TL textualization.

Once we see the text as an autonomous entity, we find it at the highest level of language units. Beyond the text, factors such as communicative situation, sociocultural environment, and genre membership serve as the pragmatic background against which the text is projected. Although this background does not overtly participate in the language operation of an actual translation act, as an extralinguistic context it has a crucial bearing (via the more direct linguistic context of the text) on the interpretation of textual elements in various language levels. As an autonomous entity, "a text operates upon and thereby changes that [nonlinguistic] context" (Ballmer 1981: 173). Downwards, the text provides its constituent units with a linguistic and conceptual context (cf. Tomlin 1995) via a sentence-based segmentational mechanism identified as a "text frame," which allows the organization of a text to be represented diagrammatically, e.g. for language teaching purposes (see McCarthy and Carter 1994: sec. 2.2.1). ${ }^{4}$ Thus, within the text the internal relationships are of a more linguistically accountable nature than the external relationships between the text and its nonlinguistic context, although this accountability reflects the norms of textualization in each language because of determinations such as "contextual, situational and intertextual referencing” (Hewson and Martin 1991: 93).

As the target and final product of a translation act, the text "changes" the nonlinguistic context, which is pertinent to the act's socio-cultural significance but not the formal and functional issues the act involves. Thus, dispite the text's status as a language unit which verifies the textual integrity of its constituent units, it is unqualified to be the UT for text translation.

\section{THE FEASIBILITY OF ACCEPTING THE SENTENCE AS THE KEY FUNCTIONAL UT}

We have argued that as long as we accept the UT as a textual unit, it does not have to obtain an ultimate textual judicial authority and does not need to be a complete text. Our task now is to locate a language unit that is sufficiently limited in size, complete in form and independent in meaning to make its textual integrity observable and preservable in translating. Scanning upwards along the language hierarchy, we can see that neither the word, the phrase, nor the clause can meet the requirements of 
completeness and independence (see Section 9 below), although all are limited in size. Thus, it is the sentence that claims our attention, at least for the moment.

In this connection, the description of the relationship between the text and the sentence in terms of context-change or contextualization offered by Ballmer is illuminating:

Contextualization is the process of compiling incoming linguistic information and packing it away by adding it to the (linguistic or nonlinguistic) context. This is exactly what punctuation signs predominantly but not exclusively do at the end of an incoming sentence. They add it to the previous [co-]text. Sentences in a text operate on the previous [co-]text in a sequential manner. (Balmer 1981: 174)

A sentence enters the text-building process as a syntactically independent but not textually autonomous entity, its independence endowed by a cognitively significant structure of combined old-new information (cf. Downing 1995) secured semantically by lower-level textual units such as words. Further down from the level of sentences, units such as clauses, phrases, words and morphemes enjoy less and less independence, degrees of which are marked by various types of punctuations (including zero punctuation) or word space. Among punctuation signs that operate to (con)textualize, full stops are the most significant marks since they signal the full sentential independence of a language segment. For this reason they have been described by Coulthard (1985: 192) as "interaction points" in discourse. (See also Nash 1992: 61-62 for an itemization of a "three-stop system of punctuation" in English, i.e. period, semi-colon and comma, which is largely applicable to the Chinese punctuation system of hierarchical meaning segmentation in a sentence.)

From the perspective of sentence linguistics, the sentence's role as an essential grammatical unit and fundamental dynamic unit of communication offers a regulated and analyzable logical formation, and a definite formal boundary. Functionally, it constitutes a relatively complete information structure in the form of a proposition (which may contain subordinary propositions) that yields to thematic analysis and/ or topic-focus assessment. (The proposition, with related elements contained in the same sentence, has actually been taken as the basic working unit by those who prefer a more logical to a more formal unit, e.g. Hewson and Martin 1991: 59.) Orthographically, the sentence has its completeness registered and acknowledged in written texts with a full stop, which prompts the "contextualization" of the information it carries. Communicatively, it contains at least one illocution to be incorporated into the text at large, although with its independence marked by the relatively low "degree of cohesion between it and the surrounding text" (cf. Eifring 1993: 19). The sentence represents a complete syntactic form with an independent information structure that as a speech act has been found to be "identifiable across languages" (Lambrecht 1994: 34-35). These sentential properties serve to demarcate the cognitive and functional basis of a sentence's textual integrity that is processed and preserved in the TL text. The sentence's status as a functional UT is thus justified. ${ }^{5}$

From the point of view of text linguistics, the sentence is the smallest complete textual unit; at lower levels, the semantic and syntactic potential of a language unit will not realize any textual significance until it has found its place in the syntactic structure of a sentence (cf. Li 1991: 2, who regards the sentence as "the smallest unit of verbalization," and has noted that the relationship between the word/phrase and 
the sentence is one of realization, while the relationship between the word and the phrase, or between the sentence and the sentence group, is one of composition). By concentrating on a sentence's textual integrity, the translator is in a better position to hold its syntactic sub-units more specifically accountable for their contribution to making the sentence a viable textual unit. In the TL text, these can be similarly accounted for through corresponding choice of words and word-order. As the smallest textual unit without an ultimate textual judicial capacity, the sentence represents an open structure which contains formal and functional coherent devices, such as the so-called "logical operators" and "interactive signals" (Sinclair 1993: 7), that allow it to be connected to its co-texts. In this way it forms the bases for the linear coherence of the text and the global coherence of macro-structures (cf. Neubert and Shreve 1992: 40, 136).

Among the language levels, therefore, the sentence is where sentence linguistics and text linguistics overlap, and textualization and communication correlate. At the same time, though, issues at other language levels may periodically surface for more specific attention. For instance, cohesive devices may vary from language to language, and may have to be treated at the level of word or phrase as elements of extrapropositional relations and textual strategies (cf. Hewson and Martin 1991: 86ff). We should note, then, that decisions made at any other language levels will be duly reflected within the contour of the sentence, the primary building block for TL text construction. In SL text interpretation and TL text construction alike, the sentence plays the role of key functional UT, although not necessarily the only functional UT.

\section{THE CLAUSE AND PARAGRAPH SEEN FROM THE SENTENCE}

At this juncture we state our position on the status of the clause. A clause, normally containing a propositional meaning, acquires full sentential independence when it is marked off, as in English, by a capital letter at its beginning and a full stop at the end. When the textual connection between two or more (simple) sentences is considered close enough to justify formal recognition, they may be tied together to form one (compound) sentence by means of formal/logical indicator(s) of cohesion and parity. In this case, the clauses concerned retain most of their "sentencehood" as coordinate clauses in textualization. Consequently, a coordinate clause is treated methodologically as a sentence. If one clause is considered subordinate to another, it has to surrender its "sentencehood" to the latter, main clause in order to form a formally/ logically and more textually close-knit unit called a complex sentence. In this case the propositional meaning of the main clause would not be complete without that of the subordinate clause, and the subordinate clause would not function textually without being attached to the main clause. Sentential independence can only be achieved on the level of the complex sentence as a whole instead of in either of the clauses taken separately.

The status of the paragraph calls for comment as well. The textual boundaries of a paragraph are orthographically marked off like those of a sentence. However, its internal formation, especially in innovative and expressive types of texts, has withstood rigorous analytical approaches such as those used to view syntax (cf. Hofmann 1989). Efforts to identify the mechanisms of paragraph development, at least in a pedagogical framework, have yielded little more than descriptive patterns - for 
instance by listing/examples, comparison/contrast, etc. (see Imhoof and Hudson 1975). However, instead of the highly regulated formulations found in sentence formations, these patterns are arrangements of sentences that furnish a certain type of argumentation in pragmatic writing (as against more sentence-based "artistic" writing).

There is no lack of cross-lingual research efforts at a higher level than the sentence. Apart from discoveries of the correlation between pronoun distribution patterns and paragraph boundaries (Hofmann 1989, Xu 1994), S. Hu (1993: 165-172) has referred to a typical "spiral structure" identified by Kaplan (1966) in Chinese paragraph formation, that is different from the linear structure in a typical English paragraph (cf. also Xiao 1992: ch. 3). Although this difference causes language learning problems in itself and quite probably reduces the textual effectiveness of an English translation of a Chinese paragraph, other questions remain. Is the translator allowed to smooth out the difference by straightening the "spiral" into a "straight line," so to speak? Would reshuffling the sentences help to improve the textual effectiveness of a TL version? If so, which of the almost innumerable possibilities is the best option?

Dividing a long paragraph into short ones or joining short paragraphs together to form a long one is paraphrasing in the mildest form, a practice not infrequently found in translation. But technically speaking, paragraph modification may not be permitted by translation companies. Can cutting a long paragraph or stretching a short one be counted as translation proper? (Neubert and Shreve 1992: 83, for instance, have noted the possible need of the translator to prune the digressions of a German scientific text when translating it into English.) As far as reparagraphing in cross-language translation is concerned, rigorous studies based on extensive observation of professional practice are still lacking. Present studies concerned with innocuous generalities, such as stressing the importance of coherence in semantic structuring (S. Hu 1993: 601), and undefinable notions, such as shensi ("resemblance in spirit") and huajing ("perfect reproduction/transmutation,") (Xiao 1992: 37), do not provide any definite and operable guidelines.

A theory of the "structural paragraph" as against "orthographic paragraph," on the other hand, has recently been advanced by Hatim (1997: ch. 6). It argues for an argumentation-related partitioning of paragraphs superimposing their indentationmarked boundaries. The practice of such a partitioning, as illustrated by the author, relies on the textual significance of key-positioned sentences as they function to mark the continuation (beyond the typographic boundaries of a paragraph), or alteration (within the typographic boundaries of a paragraph) of the direction of the text's argumentation. In this way it agrees with our highlighting of the sentence as the key functional textual unit for translation.

Normally the existing pattern of the source-text paragraph serves as the point of departure in translating. In some cases paraphrasing and/or rewriting, which include reparagraphing, are deemed necessary and advisable, either in accordance with typographical convenience, the paragraph length preference of the TL culture (see ElShiyab 1994 for an Arabic-English case), or in conformity with the system of structural paragraphs derived by the translator from source-text argumentation. ${ }^{6}$

However the translator decides, the fact remains that paragraphic patterns draw heavily on sequential arrangements of sentences for their development. This high- 
lights the necessity of regarding the sentence as the key functional unit for analyzing and constructing a paragraph in translation as well as in writing. Such a position is strengthened by Kiraly's (1995: 86) Talk-Aloud-Protocol experiments (showing that subjects rarely translated at the inter-sentential level and preferred the word string level), and by Lörscher's findings that translators "choose phrases, clauses or sentences as units of translation" while non-professionals tend to concentrate on single words (1996: 30). Findings of other studies such as Hall's (1996), which noted that after "several semesters of [...] being exposed to the cognitive approach, [translation] students were able to internalize the whole text as a translation unit", point to the (full) text as the UT. However, such studies should not to be thought to be at variance with our thesis as we understand the text to be a UT in the judicial sense (see Section 5 above).

This also explains why the size of a UT is decided by translators' techniques, their cognitive capacity and the type of document; as well as the reason experienced translators "look for equivalences at the nearest grammatical level possible" (Sager 1994: 145, 225). In a more straightforward manner, Newmark (1988: 65) notes that translators "translate sentence by sentence, and [...] will consciously be looking at the larger units" only when it is necessary to do so.

\section{TRANSLATING WITH THE SENTENCE AS KEY FUNCTIONAL UT}

Based on our discussion above, a few postulates are worth noting about translating with the sentence as the key functional UT.

First, the textual integrity of a sentence is not realized until it enters the mechanism of textualization as a syntactic bearer, information carrier, and stylistic marker. Without respect for sentential integrity, textuality will become groundless in text translation; without the authority of textuality, sentential integrity will become hingeless. In either case the construction of a target text as a coherent structure of meaning is in jeopardy. This is a basic tenet established in our study, which alerts the translator to:

(1) the relation between a sentence's internal mode of information presentation and its potential textual integrity in TL textualization;

(2) the importance of a TL sentence's thematic structure in preserving its textual integrity in relation to the whole TL text; and

(3) the necessity to align sentential speech acts with the textual speech act through appropriate syntactic management.

Secondly, in textualization the interrelations between a sentence's function-based textual integrity and that of its co-text contribute substantially to the text's coherence, and have to be closely observed in translating. To maintain such interrelations in translating demands careful attention, especially for those marked by thematic structural manipulation rather than overt cohesive clues (see Halliday 1985: sec. 9.6 for the structural and cohesive features of text formation). If we find that the thematic structure in a sentence has contributed to the SL textualization, then we will expect its counterpart to do the same in the TL text with a matching (though not necessarily identical) deployment of its componential units. This, again, calls for close observa- 
tion of the intra-sentential structure, but from the vantage point of inter-sentential coherence.

Thirdly, what makes text translation different from sentence translation is not the size of the text or the UT involved, but the emphasis on the retrieval and rebuilding of inter-sentential coherence, i.e. the mechanisms that hang the sentences together. In this study, we have argued that with sentences as key functional UTs, such cohesive factors can be more definitely accounted for in the construction of the network of thematic structures in the target text.

\section{CONCLUSION}

The mention of the UT gives the impression that taking the word as the UT means word-for-word translation, or literal translation, and that taking the sentence as the UT means sentence-for-sentence or "free" translation that "frees" the Word. When the development of text linguistics encourages translators to look upwards, one may well ask if this entails full-text-for-full-text translation where everything within the text contour is free to move or "translate." For anybody applying the concept of UT to translating, translation studies, and the teaching of translation, this perception is selfdefeating. In this article, we have identified the (potential) textual integrity of a language unit that can be realized in SL textualization, and should be restored in TL textualization. With text linguistics a translator is able to "climb up" the language hierarchy, to work more effectively from the level of text with textual judicial authority on issues that are conventionally outside the purview of sentence grammar but eventually materialize in sentence structures. More importantly, text linguistics should enable a translator to "look down" in the light of textuality at lower units as functional units. Among these functional units, we have argued, the sentence should be taken as the key unit of translation based on its textual integrity as syntactic bearer, information carrier and stylistic marker. We have also postulated that this conception of UT will help render a language unit more in keeping with its intended textual contribution in shaping the target text. Lastly, text translation can benefit from an active interaction between textual authority and sentential integrity as long as emphasis is placed more on the functional than formal aspects of a sentence.

\section{NOTES}

1. While Russian, Chinese (Fan 1994) and Arabic (Farghal 1994) theorists still actively apply the notion of equivalence (cf. Shveitser 1993 and Lefevere's chapter introduction), some Western authors use the term with caution. For instance, Baker (1992: 5-6) adopts the term "for the sake of convenience - because most translators are used to it rather than because it has any theoretical status." Neubert and Shreve (1992: 142-146, 150 note 10) argue eloquently for the notion of textual equivalence as a valid albeit "quite general" concept but modify definitions of equivalence to exclude implications of (complete) identity and/or "a relationship between textual surfaces." However, they agree about the necessity of looking into the interrelationships between textual effect (the foundation of textual equivalence) and actual textual formations or surface structures of SL and TL texts (cf. Q. Hu 1993). Similar positions are adopted by Sager (1994: 144, 224) and Toury (1995: 86).

2. In their comparative study of theories of cognitive understanding by means of binary oppositions, Schleifer et al. make reference to Jerome Bruner's identification of "two distinctive [but nevertheless complementary] ways of ordering experience or constructing reality;" information organization in our terms. One way is "the narrative mode" of "good story", and the other is "the paradigmatic or logico-scientific" mode of "well-formed argument." The former, according to Bruner, "leads to 
conclusions not about certainties in an aboriginal world, but about the varying perspectives that can be constructed to make experience comprehensible;" while the latter "yields accounts of experience that are replicable, interpersonally amenable to calibration and easy correction" (cf. Schleifer et al. 1992: 58-63).

3. Sager's (1994: sec. 4.1.3.1) position on textuality concludes that "these criteria offer no significant advance on our ability to determine textual unity," as being "highly subjective" [with the exceptions of "cohesion" and "coherence"]. The ground of his conclusion, however, needs to be re-examined. As we see it, "informativity," for instance, should not be invalidated simply because of the existence of "completely vacuous texts," which if classified as texts instead of non-texts, must be capable of serving certain purposes in a broader context. Also, by "intertextuality" we do not mean that the dependence of one text on another would logically bring the two to "form a unit." Instead, the latter, as well as any other texts that happen to be related to the text in question, should be part of the typological and cultural background against which the text performs as an individual entity. If the two texts, and by extension all interdependent texts, do come together, they will form a higher unit: "the text world" described by Neubert and Shreve (1992: 41; see also pp. 117, 120, 121 and 136-137). In an extreme sense, as Tzvetan Todorov states, "all texts can be considered as parts of a single text which has been in the writing since the beginning of time. [...] we must not underestimate the presence of other texts within the text" (as cited in Eoyang 1993: 155n). In the final analysis, it has to be noted that in Sager's (1994: 67) system, a text, as against a message, is devoid of intention; a notion of text as such is irrelevant to what the concept of textuality has been designed for.

4. Neubert and Shreve (1992: 59ff, see esp. pp. 60, 61, 64-67) have proposed another more conceptual/ experiential notion of frames to connect the text and its constituent units. Comparable to van Dijk's (1977: 99) notion of frames [of situation-related conventional knowledge], it is a useful insight into the mechanisms of text translation. However, their claim that ideal translations "should be the kind of texts that $\mathrm{L}_{1}$ senders would have formulated for $\mathrm{L}_{2}$ audiences themselves" (p. 65) sails too close to the fallacious argument for matching in reader response. There can be no definite confirmation of such "would-have" conjectures.

5. We assume translators to be skilled writers who will not "produce incredibly long sentences using the words 'and' and 'and then'" as inexperienced writers would. Our adoption of the sentence as the key functional UT seems to have indirectly found further support, therefore, in the application of the socalled T-unit in measuring the development of writing skills, given similarities between writing and translating in textual as well as philosophical terms (cf. Eoyang 1993: 126). A T-unit, or "terminable unit," according to Renkema, is "a main or independent clause with all its modifiers and subordinate clauses. Grammatically, a T-unit can be terminated with a period or other terminal mark." This notion of the T-unit, applicable in our view to English and Chinese texts alike, has replaced traditional sentence length as a unit to measure syntactic maturity in schoolchildren's and adults' use of language. It is used to obviate statistical misrepresentations that may be caused by the existence of “childish" long sentences (see Renkema 1993: 175ff, based on Kellog Hunt's research.)

6. Larson (1984), on the other hand, adopts a semantic structural hierarchy (from meaning component, concept, concept cluster, proposition, propositional cluster, semantic paragraph, episode, episode cluster, and semantic part to discourse). He holds the "semantic paragraph" as the basic UT to "focus on." According to Larson, the semantic paragraph and the ordinary grammatical paragraph "often match," given some possible skewing. As we see it, the semantic rewrite-based translation procedure advocated by Larson (Ch. 36), requires a work surface as large as the paragraph to enable room for rewriting; it could have claimed even larger units, had a larger one not been "impossible to keep clearly in mind" (cf. Larson 1984: 30-31, 36, 353-356, 479, 497). How well such a modus operandi - said to work towards the accuracy, clarity and naturalness of a rendering - can convey the source-text's form-related effect or style is open to question.

\section{REFERENCES}

Baker, Mona (1992): In Other Words: A Coursebook on Translation, London and New York, Routledge.

Bal I mer, Thomas (1981): "Words, sentences, texts, and all that", Text, 1, 2, pp. 163-189.

Barkhudar ov, Leonid (1993): "The problem of the unit of translation”, in Zl at eva (Ed. and tr.), Translation as Social Action: Russian and Bulgarian Perspectives, London and New York, Routledge, pp. 39-46. 
Bassn et t -M cguire, Susan (1980): Translation Studies, London and New York, Methuen.

Beau grande, Robert de, Abdulla Shunnaq and Mohamed H. H el iel (Eds.) (1994): Language, Discourse and Translation: in the West and Middle East, Amsterdam and Philadelphia, John Benjamins.

Bel I, Roger (1991): Translation and Translating: Theory and Practice, London and New York, Longman.

Cat f or d, J. C. (1965): A Linguistic Theory of Translation, London, Oxford University Press.

Coulthard, Malcolm (1985): An Introduction to Discourse Analysis, London and New York, Longman, 1st ed. 1977.

Cowan, Ron (1995): “What are discourse principles made of?", in Dow ning and No onan (Eds.), Word Order in Discourse, Amsterdam and Philadelphia, John Benjamins, pp. 29-49.

Downing, Pamela (1995): "Word order in discourse: By way of introduction", Downing and Noonan (Eds.), Word Order in Discourse, Amsterdam and Philadelphia, John Benjamins, pp. 1-27.

D ow ning, Pamela and Michael N o onan (Eds.) (1995): Word Order in Discourse, Amsterdam and Philadelphia, John Benjamins.

Eifring, Halvor (1993): Clause Combinations in Chines, PhD dissertation, Oslo, University of Oslo.

El -Sh iyab, Said M. (1994): “The rhetoric of paragraphing across cultures", in Beaugr an de et al. (Eds.), Language, Discourse and Translation: in the West and Middle East, Amsterdam and Philadelphia, John Benjamins, pp. 73-77.

Eoyang, Eugene (1993): The Transparent Eye: Reflections on Translation, Chinese Literature, and Comparative Poetics, Honolulu, University of Hawaii Press.

Fan, Shouyi (1994): “Translation studies in modern China: retrospect and prospect”, Target, 6 (2), pp. 151-176.

Farghal, Mohammed (1994): "Ideational equivalence in translation", in Beaugrande et al. (Eds.), Language, Discourse and Translation: in the West and M iddle East, Amsterdam and Philadelphia, John Benjamins, pp. 55-63.

Givón, T. (1978): "Universal grammar, lexical structure and translatability", in Guent hner and Guenthner-Reut ter (Eds.), M eaning and Translation: Philosophical and Linguistic Approaches, Worcester and London, Trinity Press, pp. 235-272.

H al I , Karin Riedemann (1996): “Cognition and Translation Didactics”, M eta, 41 (1), pp. 114-117.

H al I iday, M. A. K. (1978): Language as Social Semiotic: the Social Interpretation of Language and M eaning, London, Edward Arnold.

- (1985): An Introduction to Functional Grammar, London, Edward Arnold.

$\mathrm{H}$ at im, Basil (1997): Communication Across Cultures: Translation Theory and Contrastive Text Linguistics, University of Exeter Press.

$\mathrm{H}$ at im, Basil and Ian Mason (1990): Discourse and the Translator, London and New York, Longman.

Hewson, Lance and Jacky M artin (1991): Redefining Translation: The Variational Approach, London and New York, Routledge.

H of man n, Thomas R. (1989): "Paragraphs, \& anaphora", Journal of Pragmatics, 13, pp. 239-250.

Hol mes, J. S. (1988): Translated! Papers on Literary Translation and Translation Studies, Amsterdam, Rodopi.

H u, Qian (1993): “On the Implausibility of Equivalent Response (Part III)”, M eta, 38 (2), pp. 226-237.

(1994): "On the Implausibility of Equivalent Response (Part V)", M eta, 39 (3), pp. 418-432.

H u, Shuzhong (1993): Comparative Studies in English \& Chinese Rhetoric (Chinese), Shanghai, Shanghai Waiyu Jiaoyu Chubanshe.

Imh o of, Maurice and Herman H udson (1975): From Paragraph to Essay: D eveloping Composition Writing, Essex, Longman. 
Kaplan, Robert (1966): "Cultural Thought Patterns in Inter-Cultural Education”, Language Learning, 16, pp. 1-20.

Kir al y, Donald C. (1995): Pathways to Translation: Pedagogy and Process, Kent and London, Kent State University Press.

Koskinen, Kaisa (1994): "(Mis)Translating the Untranslatable - the Impact of Deconstruction and Post-structuralism on Translation Theory", M eta, 39 (3), pp. 446-452.

La mbr echt , Knud (1994): Information Structure and Sentence Form: Topics, Focus, and the M ental Representations of Discourse Referents, Cambridge, Cambridge University Press.

Lar son, Mildred L. (1984): M eaning-based Translation: A Guide to Cross-language Equivalence, Lanham, University Press of America.

Li, Ziyun (1991): Hanyu Jufa Guize [Rules of Chinese Syntax], Hefei, Anhui Jiaoyu Chubanshe. Lörscher, Wolfgang (1996): "A Psycholinguistic Analysis of Translation Processes", M eta, 41 (1), pp. 26-32.

M aso n, Ian (1994): "Discourse, ideology, and translation", in B eau gr ande et al. (Eds.), Language, Discourse and Translation: in the West and Middle East, Amsterdam and Philadelphia, John Benjamins, pp. 23-34.

M cCarthy, M. and R. A. Cart er (1994): Language as Discourse: Perspectives for Language Teaching, London, Longman.

Nash, W. (1992): An Uncommon Tongue - the U ses and Resources of English, London, Routledge. N eubert, Albrecht and Gregory M. Sh reve (1992): Translation as Text, Kent and London, Kent State University Press.

N ew mark, Peter (1981): Approaches to Translation, Oxford, New York, Pergamon Press. (1988): A Textbook of Translation, New York, London, Prentice Hall. (1991): About Translation, Clevedon, Multilingual Matters.

O 'Br ien, Justin (1959/66): “From French to English", in R. A. Br ow er (Ed.), On Translation, New York, Oxford University Press, pp. 78-92.

Pet r ey, Sandy (1990): Speech Acts and Literary Theory, New York and London, Routledge.

Sager, Juan (1994): Language Engineering and Translation Consequences of Automation, Amsterdam and Philadelphia, John Benjamins.

Schl eif er, Ronald, Robert Con Davis, and Nancy Mer gl er (1992): Culture and Cognition: the Boundaries of Literary and Scientific Inquiry, Ithaca and London, Cornell University Press.

Sh veit ser, Alexander (1993): "Equivalence and adequacy", in Zl at eva (Ed. and tr.), Translation as Social Action: Russian and Bulgarian Perspectives, London and New York, Routledge, pp. 47-56.

Sincl air , J. M. (1993): "Written discourse structure", in John M. Sincl air, Michael Hoey and Gwyneth Fox (Eds.), Techniques of D escription: Spoken and Written Discourse: a Festschrift for M alcolm Coulthard, London and New York, Routledge, pp. 6-31.

Snel I-H o r nby, Mary (1988): Translation Studies: an Integrated Approach, Amsterdam and Philadelphia, John Benjamins.

(1990): "Linguistic transcoding or cultural transfer? A critique of translation theory in Germany", in Susan Bassn et t and André Lef ever e (Eds.), Translation, History and Culture, London and New York, Pinter Publishers. 79-86.

Tan, Xuechun, Tang Yue and Zhu Ling (1992): Jieshou Xiucixue [Reception Rhetoric], Shanghai, Shanghai Jiaoyu Chubanshe.

Tancock, L.W. (1958): "Some problems of style in translation from French", in Secker and War bur g (publ.), Aspects of Translation, London, pp. 29-51.

Toml in, Russell (1995): "Focal attention, voice, and word order: an experimental, cross-linguistic study", in Downing and No onan (Eds.), Word Order in Discourse, Amsterdam and Philadelphia, John Benjamins, pp. 517-54.

To ury, G. (1995): D escriptive Translation Studies and Beyond, Amsterdam and Philadelphia, John Benjamins.

Van Dijk, T. A. (1977): Text and Context: Explorations in the Semantics and Pragmatics of Discourse, London and New York, Longman. 
W il ss, Wolfram (1982): The Science of Translation: Problems and M ethods, Tübingen, Gunter Narr. Xiao, Liming (1992): Fanyi Xin Tan [New Approaches to Translation], Taipei, Shulin Chuban Youxian Gongsi.

Xu, Jiujiu (1994): "A discourse analysis of ta in narration", in Yuyong Yanjiu Lunji [Collected Papers on Pragmatics], Beijing, Beijing Yuyan Xueyuan Chubanshe, pp. 113-136.

Zhang, Zeqian (1994): Fanyi Jingwei [Longitudes and Latitudes of Translation], Wuhan, Wuhan University Press.

Zhu, C. (1996a): "Climb Up and Look Down: On sentences as the key functional UT (Unit Of Translation) in text translation", Proceedings of the 14th World Congress of the Fédération Internationale des Traducteurs (FIT), February 1996, Vol. 1, Melbourne, AUSIT, pp. 322-343. (1996b): "From Functional Grammar and Speech Act Theory to Structure of Meaning: a Three-dimensional Perspective on Translating", M eta, 41 (3), pp. 338-355.

Zl at eva, Palma (ed. and tr.) (1993): Translation as Social Action: Russian and Bulgarian Perspectives, London and New York, Routledge. 